\title{
Potential Effect of Pitaya Fruit Juice (Hylocereus Polyrhizus) as an Anti-anemic Agent for Postpartum Anemia
}

\author{
Mufida Annisa Rahmawati, Supriyana, Masrifan Djamil \\ Applied Midwifery, Graduate Program, School of Health Polytechnics, \\ Ministry of Health Semarang
}

\begin{abstract}
Background: Postpartum mothers are susceptible to anemia, due to loss of blood during labor. Postpartum anemia causes uterine subinvolution which results in postpartum hemorrhage, puerperium infection, decreases in breastfeeding and mammae infection. One alternative to prevent the occurrence of anemia in post partum s to consume fruit that contains iron and vitamin $\mathrm{C}$ is one pitaya fruit juice. Pitaya fruit (Pitaya fruit) is part of the non-heme iron sources needed to supply hemoglobin, hematocrit and erythrocytes. This study aimed to examine the effect of pitaya fruit juice consumption on the increase of hemoglobin, hematocrit, and erythrocyte levels.

Subjects and Method: This was a quasy experiment conducted at Bumiaji health center. A sample of 32 postpartum mothers with anemia was selected for this study. The dependent variable was hemoglobin, hematocrit, and erythrocyte levels. The independent variable was pitaya fruit juice administration. The data were analyzed by paired t-test.

Results: Hemoglobin level in the intervention group (mean=11.27; $\mathrm{SD}=0.85$ ) was higher than control group (mean $=10.34 ; \mathrm{SD}=0.94)$ and it was statistically significant $(\mathrm{p}<0.001)$. Hematocrit level in the intervention group (mean=36.78; $\mathrm{SD}=3.17$ ) was higher than control group (mean= 34.98; $\mathrm{SD}=2.32$ ) and it was statistically significant ( $\mathrm{p}<0.001)$. Erythrocyte level in the intervention group (mean= 4.28; $\mathrm{SD}=0.26)$ was higher than control group (mean=3.97; $\mathrm{SD}=0.36)$ and it was statistically significant $(\mathrm{p}<0.001)$.

Conclusion: Hemoglobin, hematocrit, and erythrocyte levels are higher in the intervention group than control group and they are statistically significant.
\end{abstract}

Keywords: pitaya fruit juice, hemoglobin, hematocrit, erythrocyte, postpartum mother, anemia

\section{Correspondence:}

Mufida Annisa Rahmawati. Masters of Applied Midwifery, Health Polytechnics Ministry of Health Semarang. Jl. Tirto Agung, Pedalangan, Banyumanik, Semarang 50239, Central Java. Mobile: +6281249674231 .

\section{BACKGROUND}

The prevalence of anemia in developing countries reaches $14 \%$, and $51 \%$ in developing countries. According to World Health Organization in the incidence of anemia in postpartum mothers is $56 \%$ (Ministry of Health RI, 2017). In India maternal death due to anemia reached $19 \%$, from cases of anemia in postpartum mothers 65\%-75\%. Based on the 2012 Indonesian Demographic and Health Survey (IDHS), the maternal mortality rate in Indonesia is still high at 359 per 100,000 live births. The high maternal mortality rate and infant mortality rate illustrate that the health status of mothers and children is far from being expected. Anemia is part of the causes of maternal death.

In Indonesia, death in postpartum mothers due to anemia reaches 30\% (Ministry of Health RI, 2017). Iron deficiency anemia that occurs during the puerperium is affected by the occurrence of anemia during pregnancy and the amount of blood loss during labor. It is estimated that 300 $\mathrm{ml}$ of bleeding will result in an iron loss of 
around 130mg. This will spur the rapid loss of iron reserves (iron depletion) resulting in iron deficiency anemia (de Sousa et al., 2017).

Provision of iron tablets as prophylaxis can improve and maintain adequate iron status. So far efforts to overcome iron deficiency anemia are still focused on groups of pregnant women, while other groups such as infants, toddlers, school children, postpartum women and women of childbearing age have not been treated even though the negative impact caused by iron deficiency anemia in other groups is also very serious (Urquizu et al., 2016)

Postpartum anemia can cause uterine sub-involution which can cause post parted hemorrhage, facilitate the puerperium infection, reduce milk intake and easily develop infection. This is an indirect cause of failure of exclusive breastfeeding and a decrease in breast milk coverage (Rollett et al., 2018).

Methods to prevent the occurrence of anemia in postpartum mothers, this time efforts have been made to find herbs or plants that contain new antioxidants regarding plants that are efficacious as a drug in the management of a disease. Traditional medicine was then developed through research, testing as an alternative to the use of chemical drugs so far, especially regarding food ingredients containing iron. Sources of iron can be obtained from food from both animal and vegetable. The highest iron content comes from animal, but the price is quite expensive (Congden, 2016).

Fruits contain many essential nutriaents, including various vitamins, minerals such as calcium, iron and many others. A study by Arifin (2012) states that pitaya fruit can increase iron levels and increase hemoglobin levels in the blood (Arifin, 2012).

\section{SUBJECTS AND METHOD \\ 1. Study Design}

This is a quasy experimental with pre post test control group design. The study was conducted in the Community Health Center of Bumiaji, East Java, from June to July 2018.

\section{Population and Samples}

The sources population in this study was post partum mothers with anemia in Bumiaji Community Health Center. A sample of 32 post partum mothers was selected by fixed disease sampling.

\section{Study Variables}

The dependent variables were hemoglobin level, erythrocyte count, and hematocrit level. The independent variable was pitaya fruit juice administration.

\section{Operational Definition of Variables}

Pitaya fruit juice is made from $500 \mathrm{~g}$ of pitaya fruit processed with a juicer machine, 400cc of pitaya fruit juice is obtained and taken once a day. Data have a nominal scale. Hemoglobin level is the value of hemoglobin gr\% in the blood. The number of erythrocytes is the most abundant type of blood cell that functions to carry oxygen to the body's tissues and consists of hemoglobin. The amount of hematocrit is the percentage of red blood cells to total blood volume and a decrease in hematocrit is an indicator of anemia. Each of these data has an interval scale.

\section{Study Instrument}

The data were collected by questionnaire. Hemoglobin, hematocrit, and erythrocyte levels were measured by hematology analyzer

\section{Data Analysis}

Data analysis using paired t-test to examine the effect of giving pitaya fruit juice to overcome the incidence of anemia in post partum mothers who received Fe tablets. 


\section{Research Ethics}

Ethical research was obtained from Research Ethics Committee, Ministry of Health, Health Polytechnics Semarang, Central Java, with Number: 445/KEPK/ Poltekkes-Smg / EC / 2018.

\section{RESULTS \\ 1. Univariate Analysis \\ Table 1 shows the average age of mothers in the treatment group was 26.13 years, whereas in the control group the average} Table 1. Univariate Analysis

\begin{tabular}{llcc}
\hline & & Intervention & Control \\
\hline Age & Mean & 26.13 & 27.00 \\
& SD & 4.37 & 5.203 \\
Body Mass Index & Min-Max & $21-34$ & $19-35$ \\
& Mean & 22.03 & 22.40 \\
& SD & 1.79 & 2.71 \\
Education & Min-Max & $19.72-26.56$ & $18.31-27.20$ \\
& Mean & 1.94 & 2.31 \\
& SD & 0.77 & 0.70 \\
& Min-Max & $1-3$ & $1-3$ \\
\hline
\end{tabular}

\section{Bivariate Analysis}

Table 2 showed the difference of hemoglobin level before and after pitaya fruit juice administration between control and intervention groups. age of mothers was 27 years. The average body mass index (80.0\%) of respondents in the treatment group, body mass index (BMI) is normal, as well as in the control group (78.3\%) has a normal body mass index (BMI). Based on the level of education, in the treatment group most (43.8\%) respondents in the treatment group had junior high school education, while in the control group most (43.8\%) respondents had junior and senior high school education.

Table 2. Hemoglobin level before and after pitaya fruit juice administration between treatment and control groups

\begin{tabular}{lcccccc}
\hline \multicolumn{1}{c}{$\begin{array}{c}\text { Hemoglobin } \\
\text { Level (g/dL) }\end{array}$} & \multicolumn{2}{c}{ Before intervention } & \multicolumn{2}{c}{ After intervention } & p \\
\cline { 2 - 5 } & Mean \pm SD & Min-max & Mean \pm SD & Min-max & \\
\hline Intervention & $9.89 \pm 0.88$ & $8.6-12.1$ & $11.27 \pm 0.85$ & $9.1-13.4$ & $<0.001$ \\
Control & $9.99 \pm 0.88$ & $8.7-12.1$ & $10.34 \pm 0.94$ & $9.1-12.3$ & $<0.001$ \\
\hline
\end{tabular}

Tabel 3. Hematocrit level before and after pitaya fruit juice administration between treatment and control groups

\begin{tabular}{lccccc}
\hline \multicolumn{1}{c}{ Hematocrit } & \multicolumn{2}{c}{ Before intervention } & \multicolumn{2}{c}{ After intervention } & \multirow{2}{*}{ p } \\
\cline { 2 - 5 } \multicolumn{1}{c}{ Level (g/dL) } & mean \pm SD & Min-max & Mean \pm SD & Min-max & \\
\hline Intervention & $33.94 \pm 3.55$ & $29.0-40.9$ & $36.78 \pm 3.17$ & $31.7-43.3$ & $<0.001$ \\
Control & $34.23 \pm 2.53$ & $28.8-36.8$ & $34.98 \pm 2.32$ & $30.0-38.4$ & $<0.001$ \\
\hline
\end{tabular}

Table 4 showed the difference of erythrocyte level before and after pitaya fruit juice administration between control and intervention groups. 
Table 4. Total of erythrocyte erythrocytes before and after pitaya fruit juice administration

\begin{tabular}{lccccc}
\hline \multicolumn{1}{c}{$\begin{array}{c}\text { Erythrocyte } \\
\text { Level (g/dL) }\end{array}$} & \multicolumn{2}{c}{ Before intervention } & \multicolumn{2}{c}{ After intervention } & p \\
\cline { 2 - 5 } & Mean \pm SD & Min-max & Mean \pm SD & Min-max & \\
\hline Intervention & $3.80 \pm 0.45$ & $3.25-4.65$ & $4.28 \pm 0.26$ & $3.82-4.87$ & $<0.001$ \\
Control & $3.77 \pm 0.34$ & $3.23-4.28$ & $3.97 \pm 0.36$ & $3.42-4.53$ & $<0.001$ \\
\hline
\end{tabular}

Table 5. The results of independent $t$ test after pitaya juice administration between intervention and control groups

\begin{tabular}{|c|c|c|c|}
\hline \multirow{2}{*}{ Indicator } & \multicolumn{2}{|c|}{ Groups } & \multirow{2}{*}{$\mathbf{p}$} \\
\hline & Intervention & Control & \\
\hline Hemoglobin & & & \\
\hline $\begin{array}{l}\text { Mean } \pm \text { SD } \\
\text { Hematocrit }\end{array}$ & $11.27 \pm 0.85$ & $10.34 \pm 0.95$ & $<0.001$ \\
\hline $\begin{array}{l}\text { Mean } \pm \text { SD } \\
\text { Erythrocyte }\end{array}$ & $36.78 \pm 3.17$ & $34.98 \pm 2.32$ & $<0.001$ \\
\hline Mean \pm SD & $4.28 \pm 0.26$ & $3.97 \pm 0.36$ & $<0.001$ \\
\hline
\end{tabular}

Table 5 showed that after pitaya fruit juice administration, hemoglobin level in the intervention group was higher $($ mean $=$ 11.27; $\mathrm{SD}=0.85$ ) than control group (mean $=10.34 ; \mathrm{SD}=0.94)$ and it was statistically significant $(\mathrm{p}<0.001)$.

Hematocrit level in the intervention group was higher $($ mean $=36.78 ; \mathrm{SD}=3.17)$ than control group (mean $=34.98 ; \mathrm{SD}=$ 2.32) and it was statistically significant $(\mathrm{p}<0.001)$.

Erythrocyte level in the intervention group was higher $($ mean $=4.28 ; \mathrm{SD}=0.26)$ than control group (mean $=3.97 ; \mathrm{SD}=0.36)$ and it was statistically significant $(\mathrm{p}<0.001)$.

\section{DISCUSSION}

\section{Sample characteristics}

Nutritional status in the study can be seen from the BMI. The lowest BMI in the intervention group was 19.72 and the highest was 26.56. While the highest BMI in the control group was 18.31 and the lowest was 27.20.

Nutritional status is a condition of a person caused by a lack of body needs due to an imbalance between nutrients that enter the body with the body's need for nutrients that increase during childbirth, because it is needed for the process of recovery of post-natal organs and lactation (Pereira et al., 2017).

The average age of mothers in the treatment group was 26 years old, while in the control group was 27 years old. Age 2035 years is a healthy production age where complications are rare during pregnancy, labor and childbirth because physiologically and psychologically the body's organs and emotional aspects are mature to reproduce. The younger and older the age of a mother will give birth to the nutritional needs needed (Urquizu et al., 2016).

The results of this study showed that 43.8\% study subjects in the treatment group had education <senior high school. Education influences the ability to think. In other words, someone with a higher education will be able to make a more rational decision, generally open to accept changes or new things compared to individuals with low education. A low level of maternal education is believed to influence the reception of information so that knowledge of anemia and its related factors is limited, especially 
the knowledge of the importance of iron that is needed by both mother and baby (Lukose et al., 2014).

2. Mechanism of pitaya fruit juice (Hylocereus polyrhizus) in hemoglobin metabolism process

Based on the results of statistical tests that have been conducted to see the difference in hemoglobin levels between the control groups that consume standard therapy from the health center, namely Fe tablet supplementation with the treatment group that consumed standard therapy from the health center in the form of Fe tablets and added pitaya fruit juice, showed significant differences in levels hemoglobin in both groups. Based on statistical tests after being intervened by consuming standard therapy from the health center regularly for 14 days, the average hemoglobin level, the control group experienced an average increase of 10.338. While the average hemoglobin level in the treatment group consumed standard therapy from the health center and given pitaya fruit juice regularly for 14 days, it increased to 11,269 .

Iron is also needed by the body to form hemoglobin in erythrocytes in the bone marrow, offsetting a small amount of iron that is constantly secreted by the body, and to compensate for iron loss due to bleeding and lactation for milk secretion. Iron absorption occurs in the proximal jejunum. The absorption of hem from nonanimal foods takes place more easily and efficiently because it is absorbed completely (the shape of the ferry in the hem) without being broken down first into free iron. Nonhem iron in foods and salts of inorganic or other complex iron must be converted first into free iron in the form of ferrous before being absorbed by intestinal mucosal cells (Rubio-Álvarez et al., 2017).

The high content of vitamin $\mathrm{C}$ in pitaya fruit greatly helps the process of absorption of non-heme iron by changing the shape of the ferry to ferrous so as to facilitate the body in the process of iron absorption. The high iron and vitamin $\mathrm{C}$ content in pitaya fruit causes iron to be absorbed more easily by the body 4 times faster than without vitamin C (Rodeo et al., 2018).

\section{Mechanism of pitaya fruit juice (Hylocereus polyrhizus) in ery- throcyte metabolism process}

The average number of erythrocytes in the control group who consumed standard therapy from the health center, namely supplementation of Fe tablets was lower than the average number of erythrocytes in the treatment group that consumed standard therapy from the health center in the form of supplementation of Fe tablets and supplemented with pitaya fruit juice. Based on statistical tests after being intervened by consuming standard therapy from health centers regularly for 14 days, the average number of erythrocytes in the control group experienced an average increase of 3.97 for erythrocytes. Whereas the average number of erythrocytes in the treatment group that consumed standard therapy from the health center and were given pitaya fruit juice regularly for 14 days increased to 4,2756 for erythrocytes.

Fe content in pitaya fruit plays a role in the maturation process of erythrocyte cells, the spinal cord requires many other precursors for effective erythropoiesis. These precursors include iron ( $\mathrm{Fe}$ ), vitamin $\mathrm{C}$, vitamin $\mathrm{E}$, vitamin B12, thiamine, riboflavin and oxygen (O2) needed by the erythropoietin hormone (Tenore et al., 2012).

\section{Mechanism of pitaya fruit juice \\ (Hylocereus polyrhizus) in hema- tocrit metabolism}

The average hematocrit level of the control group who consumed standard therapy from the health center, namely supple- 
mentation of $\mathrm{Fe}$ tablets was lower than the average hematocrit level of the treatment group which consumed standard therapy from the health center in the form of supplementation of Fe tablets and supplemented with pitaya fruit juice. Based on statistical tests after being intervened by consuming standard therapy from health centers regularly for 14 days, the average hematocrit level in the control group experienced an average increase of 34.98 for hematocrit. While the average hematocrit level in the treatment group that consumed standard therapy from the health center and given pitaya fruit juice regularly for 14 days, increased to 36,781 for hematocrit.

Hematocrit examination describes a percentage comparison between red blood cells, white blood cells and platelets to the whole blood volume or concentration (\%) of erythrocytes in $100 \mathrm{ml} / \mathrm{dL}$ throughout the blood. This examination is usually performed in conjunction with hemoglobin ( $\mathrm{Hb})$ and erythrocyte examinations (RubioAlvarez et al., 2017). Hematocrit values are used to determine the average erythrocyte value and to find out whether there is an anemic. Determination of hematocrit values can be done by macro and micro methods. The normal value for women is $37-43$ vol\%. Determination of hematocrit can be done carefully, average methodic error is $\pm 2 \%$ et al., 2016).

\footnotetext{
AUTHOR CONTRIBUTIONS

Mufida Annisa Rahmawati selected the study subjects, collected the data, measured hematocrit, hemoglobin, and erythrocyte levels, and wrote the manuscript. Supriyana gave theoretical suggestion on the effect of the effect of pitaya fruit juice on hematocrit, hemoglobin, and erythrocyte levels. Masrifan Djamil did the data analysis and interpreted the results of data analysis.
}

\section{CONFLICT OF INTEREST}

We declare that we do not have any conflict of interest.

\section{FUNDING AND SPONSORSHIP}

There is no external fund and sponsorship.

\section{ACKNOWLEDGEMENT}

We would like to thank to the Bumiaji health center for giving permission to do this study.

\section{REFERENCE}

Arifin H, Nofiza W, Elisma (2012). Pengaruh pemberian jus buah naga Hylocereus undatus (Haw.) Britt \& Rose terhadap jumlah hemogloin, eritrosit dan hematokrit pada mencit putih betina. Jurnal Sains dan Teknologi Farmasi, 17(2): 118-125.

Congden KA (2016). Perinatal education and support program: Baystate's New Beginnings. The Journal of Perinatal Education, 25(2): 97-104. doi: 10.1891/1058-1243.25.2.97.

Kemenkes RI (2017). Survei Demografi dan Kesehatan Indonesia 2013.

Lukose A, Ramthal A, Thomas T, Bosch R, Kurpad AV, Duggan C, Srinivasan K (2014). Nutritional factors associated with antenatal depressive symptoms in the early stage of pregnancy among Urban South Indian women. Maternal and Child Health Journal, 18(1): 161170. doi: 10.1007/s10995-013-1249-2.

Pereira TRC, Souza FGD, Beleza ACS (2017). Implications of pain in functional activities in immediate postpartum period according to the mode of delivery and parity: an observational study. Brazilian Journal of Physical Therapy. Associação Brasileira de Pesquisa e Pós-Graduação em 
Fisioterapia, 21(1): 37-43. doi: 10.1016/j.bjpt.2016.12.003.

Rodeo AJ, Castro A, Esguerra E (2018). Postharvest handling of dragon fruit (Hylocereus spp.) in the Philippines.

Rollett RA, Douglas HE, Jackson P, Wiper JD (2018). Free flap reconstruction for trauma in the early post-partum period. Journal of Plastic, Reconstructive and Aesthetic Surgery. Elsevier, 71(5): 760-761. doi: 10.1016/j.bjps.2017.11.025.

Rubio-Álvarez A, Molina-Alarcón M, Hernández-Martínez A (2017). Relationship between the degree of perineal trauma at vaginal birth and change in haemoglobin concentration. Women and Birth. Australian College of Midwives, 30(5): 382-388. doi: 10.1016/j.wombi.2017.02.015. de Sousa TM, Maioli TU, Dos Santos ALS, Dos Santos LC (2017). Energy expenditure in the immediate postpartum period: Indirect calorimetry versus predictive equations. Nutrition. Elsevier Inc., 36-42. doi: 10.1016/j.nut.2017.02.009.

Tenore GC, Novellino E, Basile A (2012). Nutraceutical potential and antioxidant benefits of red pitaya (Hylocereus polyrhizus) extracts. Journal of Functional Foods. Elsevier Ltd, 4(1): 129-136. doi: 10.1016/j.jff.2011.09.003.

Urquizu IBX, Rodriguez CM, García FA, Perez PE (2016). Anaemia in pregnancy and in the immediate postpartum period. Prevalence and risk factors in pregnancy and childbirth. Medicina Clínica. 146(10): 429-435. doi: 10.1016/j.medcle.2016.06.050. 